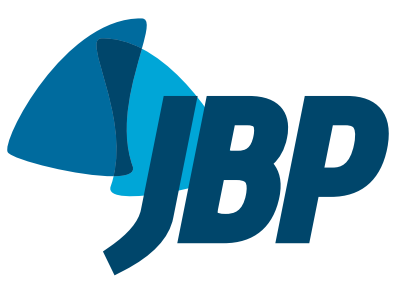

1. Departamento de Pediatria, Faculdade de Medicina, Universidade Federal de Minas Gerais - UFMG -

Belo Horizonte (MG) Brasil.

2. Departamento de Pediatria, Escola Paulista de Medicina, Universidade Federal de São Paulo - Unifesp São Paulo (SP) Brasil.

a. (D) http://orcid.org/0000-0001-6836-5725

b. (iD) http://orcid.org/0000-0003-3607-8857

c. iD http://orcid.org/0000-0003-4731-291X

d. (iD) http://orcid.org/0000-0002-3579-0861

e. (iD) http://orcid.org/0000-0002-9971-7620

Submitted: 18 March 2017

Accepted: 10 July 2017

Study carried out in the Departamento de Pediatria, Faculdade de Medicina, Universidade Federal de Minas Gerais UFMG - Belo Horizonte (MG) Brasil.

\section{Factors associated with asthma expression in adolescents}

\author{
Silvia de Souza Campos Fernandes, \\ Cláudia Ribeiro de Andrade ${ }^{1, e}$, Cássio da Cunha Ibiapina ${ }^{1, \mathrm{~b}}$
}

\begin{abstract}
Objective: To evaluate risk factors associated with asthma symptoms in adolescents in the 13- to 14-year age bracket. Methods: This was a cross-sectional study involving adolescents enrolled in randomly selected public schools in the city of Belo Horizonte, Brazil, and conducted with the use of the International Study of Asthma and Allergies in Childhood (ISAAC) questionnaire and its supplementary module for risk factor assessment. The ISAAC questionnaire was completed by the students themselves, whereas the supplementary questionnaire was completed by their parents or legal guardians. Variables showing $p \leq 0.25$ in the univariate analysis were included in the multivariate analysis. Stepwise regression with backward elimination was used for variable selection. Results: We evaluated 375 adolescents, 124 (33.1\%) of whom had asthma symptoms. The final multivariate analysis model revealed that asthma symptoms were associated with birth weight $<2,500 \mathrm{~g}$ ( $p<0.001)$, day care center or nursery attendance $(p<0.002)$, maternal history of asthma $(p<0.001)$, contact with animals during the first year of life $(p<0.027)$, current contact with animals outside the home (dogs, cats, or farm animals; $p<0.005$ ), and more than 20 cigarettes per day smoked by parents or other household members $(p<0.02)$. Conclusions: Exposure to animals in and outside the home is associated with asthma symptoms, as is environmental tobacco smoke exposure. Families, health professionals, and administrators of health care facilities should take that into account in order to prevent asthma and reduce asthma morbidity.
\end{abstract}

Keywords: Asthma; Risk factors; Adolescent.

\section{INTRODUCTION}

Asthma is multicausal and is determined by genetic, epigenetic, and environmental factors. ${ }^{(1)}$ Epidemiological studies have shown that the prevalence of asthma symptoms has increased among adolescents, although only slightly; however, the prevalence of asthma symptoms among adolescents in Latin America has been reported to have increased significantly. ${ }^{(2,3)}$

Risk factors for childhood asthma include changes in maternal diet, increased fetal growth, reduced family size, reduced prevalence of infant infection, increased use of antibiotics, and increased immunizations; however, none of the aforementioned factors can, in and of itself, explain the increased prevalence of childhood asthma. ${ }^{(4)}$ It is likely that the aforementioned socioeconomic and environmental changes have caused the infant immune system to be shifted toward a Th2 immune response, which is observed in atopic individuals. ${ }^{(5,6)}$

Given that environmental factors play an important role in the prevalence of asthma, the objective of the present study was to evaluate risk factors associated with asthma symptoms in adolescents, in order to propose measures to reduce the risk of asthma or reduce asthma morbidity in this population.

\section{METHODS}

This was a cross-sectional study involving adolescents enrolled in public schools in the city of Belo Horizonte, Brazil, and conducted between May and December of 2012 with the use of the International Study of Asthma and Allergies in Childhood (ISAAC) questionnaire. The ISAAC questionnaire was designed to determine the prevalence and severity of symptoms of asthma, allergic rhinitis, and atopic eczema, (7) and was complemented by another questionnaire, which included known and potential risk factors for asthma. ${ }^{(8)}$

According to the ISAAC protocol, the study population should comprise at least 3,000 students in the 13- to 14-year age bracket. In order to achieve the required sample size, a total of 14 elementary schools were randomly selected from a list provided by the Belo Horizonte Municipal Department of Education and including the number of enrolled students per school and grade. In order to facilitate the operationalization of the study, only schools in which there were at least 200 students in the aforementioned age bracket were considered for participant recruitment. The schools were randomly selected from a list that was randomly generated in the program Epi Info, version 6.04.

Correspondence to:

Cássio da Cunha Ibiapina. Departamento de Pediatria da Faculdade de Medicina, Universidade Federal de Minas Gerais. Avenida Professor Alfredo Balena, 190 Sala 267, CEP 30130-100, Belo Horizonte, MG, Brasil.

Tel.: 5531 3409-9772. E-mail: cassioibiapina@terra.com.br

Financial support: None. 
The supplementary questionnaire had previously been translated to Portuguese and adapted for use in Brazil on the basis of phase II of the ISAAC and consists of 33 questions regarding factors that might be associated with asthma, including birth weight and prematurity; breastfeeding; number of siblings; day care center/nursery attendance; family history of asthma (having a parent with a diagnosis of asthma); vaccination; household exposure to pets (dogs, cats, and other furry animals, as well as birds); contact with animals outside the home (including dogs, cats, and farm animals); maternal smoking during pregnancy; passive exposure to tobacco smoke (presence of smokers in the home); exposure to household mold and moisture; nutrition; and area of residence (i.e., urban, suburban, or rural residence). ${ }^{(9)}$

\section{Sample size}

Sample size was calculated by the following formula:

$$
n=\frac{N}{1+\frac{N-1}{P Q}\left(\frac{d}{Z_{\alpha / 2}}\right)^{2}}
$$

where $N$ is the total population size (i.e., 3,000 students); $P Q$ represents population variability; $d$ is the margin of error; $a$ is the level of significance (5\%); and $z_{\alpha / 2}$ is the value in the standard normal table (1.96).

Population variability was considered to be unknown, the maximum variability (i.e., 0.25 , with $P$ and $Q=$ 0.50 ) therefore being used. For a collected population of 3,000 students and a sample of 375 students, the estimation error margin is $4.8 \%$ within a $95 \%$ confidence interval. This means that if 100 surveys were conducted simultaneously by the same methods, the results of 95 would be within the estimated margin of error (i.e., $4.8 \%$ ).

Subgroups were randomly selected, and the parents or legal guardians of 200 adolescents classified as having active asthma (i.e., those who answered "yes" to the question "Have you had wheezing or whistling in the chest in the past 12 months?") and 400 controls (i.e., those who answered "no" to the aforementioned question) received the supplementary questionnaire to be completed at home and returned to the researchers on a pre-scheduled day.

\section{Definitions}

The study population was divided into two subgroups, namely, active asthma, which comprised individuals who had had wheezing in the past 12 months, and control, which comprised individuals who had had no wheezing in the past 12 months.

\section{Inclusion and exclusion criteria}

Students in the 13- to 14-year age bracket and enrolled in the selected schools were included in the study provided that they had completed the standard questionnaire; in the subsequent phase of the study, the parents or legal guardians of those students completed the supplementary questionnaire.

\section{Statistical analysis}

Univariate and multivariate analyses were performed in order to identify factors associated with asthma symptoms. Variables showing $\mathrm{p} \leq 0.25$ in the univariate analysis were included in the multivariate analysis. Stepwise regression with backward elimination was used for variable selection. The Wald test was used in order to determine whether any given factor had, in and of itself, an effect on the observed response (presence or absence of wheezing). Only the variables with a value of $p<0.05$ remained in the final model. Data were analyzed with the use of the Statistical Package for the Social Sciences, version 14.0 (SPSS Inc., Chicago, IL, USA).

\section{Ethical considerations}

The research project was approved by the Research Ethics Committee of the Federal University of Minas Gerais on January 18, 2006 (Protocol no. 237) and by the Belo Horizonte Municipal Department of Education. After permission was granted by all 14 school boards, written informed consent was obtained from all participating adolescents and their parents or legal guardians.

\section{RESULTS}

The study sample consisted of 3,325 adolescents. A total of 592 adolescents were included in the analysis of risk factors associated with asthma symptoms. After participants had been subdivided into two groups (i.e., with and without wheezing in the past 12 months) and after their parents or legal guardians had completed the supplementary questionnaire, 217 questionnaires were excluded because they had been incorrectly completed or had missing information. Therefore, the final study sample consisted of 375 adolescents, who were divided into two groups: active asthma ( $\mathrm{n}$ $=124)$ and control $(n=251)$.

Of the adolescents in the active asthma group, $42.7 \%$ were 13 years of age and $57.3 \%$ were 14 years of age; of those in the control group, $48.6 \%$ were 13 years of age and $51.4 \%$ were 14 years of age.

Table 1 shows the variables that were significantly associated with asthma symptoms in the study sample. Table 2 shows the results of the multivariate analysis. After adjustment by the multivariate logistic regression model, the following variables remained associated with asthma symptoms: birth weight $<2,500 \mathrm{~g}$; day care center or nursery attendance; maternal history of asthma; contact with animals during the first year of life; current contact with animals outside the home; and presence of household smokers smoking more than 20 cigarettes per day.

\section{DISCUSSION}

The present study showed that the following factors were associated with wheezing in adolescents: birth weight $<2,500 \mathrm{~g}$; day care center or nursery 
Table 1. Univariate analysis: variables associated with wheezing in the 12 months prior to the administration of the two questionnaires and showing $\mathrm{p} \leq 0.25$.

\begin{tabular}{lc}
\multicolumn{1}{c}{ Variable } & $\mathbf{p}$ \\
Birth weight (up to $2,499 \mathrm{~g}$ ) & 0.014 \\
Day care center or nursery attendance & $<0.001$ \\
Maternal history of asthma & $<0.001$ \\
Current presence of birds in the home & 0.021 \\
Current presence of other animals in the home & 0.108 \\
Presence of pets in the home in the first year of life (dogs, cats, other furry animals, or birds) & 0.047 \\
Current contact with farm animals & 0.187 \\
Contact with animals outside the home (dogs, cats, or farm animals) & 0.004 \\
Contact with animals outside the home in the first year of life & 0.038 \\
Current maternal smoking & 0.065 \\
Smoking in the home by parents or other household members & 0.194 \\
Number of cigarettes smoked in the home by parents or other household members (> 20 cigarettes/day) & 0.003 \\
Current absence of windows in the bedroom & 0.116 \\
Current use of bedspreads/blankets as bed linen & 0.118 \\
Use of other materials as bed linen in the first year of life & 0.105 \\
Current area of residence (suburban residence with parks or urban residence without parks) & 0.147 \\
\hline
\end{tabular}

Table 2. Final multivariate analysis model of factors associated with wheezing in the past 12 months.

\begin{tabular}{|c|c|c|c|c|}
\hline Variable & Coefficient & Wald $c^{2}$ & OR (95\% CI) & $\mathbf{p}$ \\
\hline Intercept & -1.664 & 70.978 & - & $<0.001$ \\
\hline Birth weight $<2,500 \mathrm{~g}$ & 1.055 & 14.539 & $2.9(1.7-4.9)$ & $<0.001$ \\
\hline Day care center/nursery attendance & 0.738 & 9.194 & $2.1(1.3-3.4)$ & 0.002 \\
\hline Maternal history of asthma & 0.949 & 10.456 & $2.6(1.5-4.6)$ & 0.001 \\
\hline $\begin{array}{l}\text { Contact with animals in the first year of life } \\
\text { (dogs, cats, other furry animals, or birds) }\end{array}$ & 1.152 & 4.871 & $3.2(1.1-8.8)$ & 0.027 \\
\hline $\begin{array}{l}\text { Current contact with animals outside the home } \\
\text { (dogs, cats, or farm animals) }\end{array}$ & 1.145 & 7.886 & $3.1(1.4-7.0)$ & 0.005 \\
\hline $\begin{array}{l}\text { Number of cigarettes smoked in the home by parents or } \\
\text { other household members ( }>20 \text { cigarettes/day) }\end{array}$ & 1.288 & 5.434 & $3.6(1.2-10.7)$ & 0.020 \\
\hline
\end{tabular}

attendance; maternal history of asthma; contact with animals during the first year of life; current contact with animals outside the home; and more than 20 cigarettes per day smoked in the home.

There is controversy in the literature regarding low birth weight. Although many authors have postulated that low birth weight indicates an unfavorable intrauterine environment resulting in impaired lung growth and reduced airway caliber, ${ }_{(10-12)}$ others have found no such association, the fact that associated prematurity is not excluded being often cited as a bias. ${ }^{(1,13)}$ In the present study, this issue was addressed by the question "Was your child born on the due date?" This might have played a role in minimizing the importance of that finding. In addition, the possibility of recall bias on the part of the parents or legal guardians was increased by the fact that our study involved adolescents in the 13- to 14-year age bracket.

Day care center or nursery attendance is known to be associated with recurrent wheezing or asthma depending on age. It increases the risk of recurrent wheezing in children who are 2 years of age or younger and in those in the 4- to 5-year age bracket. ${ }^{(14,15)}$ However, in 7-year-olds, no association has been found between asthma and day care center attendance. ${ }^{(16,17)}$
In children in the 5- to 14-year bracket, asthma has been found to be inversely associated with attending a day care center. ${ }^{(18)}$ According to Ball et al., attending a day care center in the first years of life is a risk factor for wheezing associated with lower respiratory tract infections in infants and also a protective factor for atopic wheezing later in life; this is probably due to Th2 response inhibition caused by infections that elicit a Th1 response at a stage that is crucial in the expansion and maturation of Th2 memory cells. ${ }^{(19)}$ Therefore, the findings of the present study should be taken into consideration despite the fact that they do not fit any of the aforementioned hypotheses. In this context, possible explanations include the presence of one or more risk factors (e.g., family history) strongly influencing clinical progression ${ }^{(20)}$; the number of children attending the same day care center ${ }^{(20)}$; and time spent in day care center environments. Cheng et al. found that spending more than 37.5 hours per week in day care center environments was associated with a reduced risk of asthma $(O R=0.6)$. ${ }^{(21)}$ Therefore, early exposure to infections through day care center attendance can be a risk factor or a protective factor for allergic diseases such as asthma (including atopic 
and nonatopic asthma), although this relationship remains unclear. ${ }^{(22)}$

Burke et al. analyzed studies conducted in more than 20 countries in all geographical regions of the world and found a consistent association between a family history of asthma and an increased risk of developing asthma, with ORs of 1.5-9.7 in cases of first-degree relatives with a history of asthma. ${ }^{(23)}$ The present study confirmed the aforementioned association, a maternal history of asthma being found to be a risk factor for asthma symptoms in adolescents (OR $=2.6$; $95 \% \mathrm{CI}$ : 1.5-4.6). Lima et al. studied 3,069 adolescents in the 13- to 14-year age bracket using the same methodology as that used in the present study and confirmed the association between a family history of asthma and an increased risk of developing asthma $(O R=2.72)$ in the city of São Luís, Brazil. ${ }^{(24)}$ In a recent study by Valadares et al., the aforementioned association was demonstrated by lung function changes in $30.3 \%$ of the children whose mothers had been diagnosed with asthma, an obstructive pattern being observed in $14 \%$. ${ }^{(25)}$ Therefore, a family history of asthma, particularly a maternal history of asthma, warrants preventive environmental measures, such as reducing exposure to aeroallergens and combating passive and active smoking. In addition, it assists in establishing a diagnosis of asthma. ${ }^{(23)}$

The relationship between exposure to animals and allergic disease is controversial. On the one hand, exposure to animal allergens can result in allergic disease ${ }^{(26)}$; on the other hand, it can confer protection against it by promoting tolerance and by modulating the immune system via bacterial endotoxins or different microbial agents. ${ }^{(27)}$ In addition, families in which there is a history of atopy tend to avoid having pets in the home. ${ }^{(28)}$ In the present study, contact with animals in the first year of life and current contact with animals outside the home were found to be associated with asthma symptoms in adolescents. In Brazil, two studies involving adolescents and employing the same methodology examined the aforementioned association. In the city of Taubaté, Toledo et al. analyzed 807 adolescents, $55.6 \%$ of whom kept furry animals, birds, or both types of animals as pets, which were kept in the home in 34\% of the cases. ${ }^{(29)}$ The authors found no significant correlation between "wheezing in the past 12 months" and the presence of pets ( $p$ $=0.9$ ), speculating on the role of antigenic load and duration of antigen exposure. ${ }^{(29)}$ In the city of Cuiabá, Jucá et al. ${ }^{(30)}$ found that currently keeping pets in the home constituted a risk factor for active asthma and emphasized the importance of factors influencing this association, including the time at which the pet was owned, child age at exposure, number of animals, allergen load in the home, and family history of atopy. Therefore, the aforementioned factors might modulate the expression of sensitization to animal allergens. ${ }^{(31)}$

According to the World Health Organization, approximately half of the children in the world are exposed to tobacco smoke, primarily in their own homes. (32) Environmental tobacco smoke exposure has adverse effects on the health of children from conception to adolescence; it is estimated that children living with smoking parents passively smoke $30-150$ cigarettes per year. ${ }^{(33)}$ Tanaka et al. found that current heavy passive smoking was related to an increase in the prevalence of wheezing and asthma, particularly in children with a family history of allergy ${ }^{(34)}$; other authors have reported that there is an increase in respiratory symptoms such as nocturnal cough, ${ }^{(35)}$ exercise-induced wheezing, ${ }^{(36)}$ and nocturnal awakenings caused by wheezing, especially if more than 10 cigarettes per day are smoked in the home $(O R=2.02){ }^{\text {(37) }}$ The present study found a trend toward an association between wheezing and smoking more than 20 cigarettes per day in the home, a finding that is consistent with those of Mitchell et al.,(38) who showed clear evidence of a dose-dependent effect for current maternal smoking on current wheezing and the severity of asthma symptoms in children in the 6- to 7-year age bracket. According to the authors, the more the mother smokes, the greater the risk of severe asthma symptoms (1-9 cigarettes/day: OR = 1.27; 10-19 cigarettes/day: $O R=1.35$; and more than 20 cigarettes/day: OR $=1.56)$. ${ }^{\text {(38) }}$ Therefore, cigarette smoke exposure can increase susceptibility to allergic sensitization in genetically predisposed individuals, leading to suppression of Th1-produced IFN-y. ${ }^{(39)}$ However, questionnaire-based assessment of environmental tobacco smoke exposure can overestimate or underestimate the effects of passive smoking on children. Therefore, biochemical markers such as cotinine can estimate environmental tobacco smoke exposure more accurately, cotinine levels correlating well with the number of cigarettes smoked and the self-reported number of cigarettes smoked. (40)

One strength of the present study is the use of a questionnaire previously validated for use Brazil.(9) Our study sample was representative, and the results can be extrapolated to the general population despite the number of questionnaires that were excluded from the study, given that multivariate analyses should include 10-20 participants per variable. Potential limitations of the present study include those inherent to questionnaire-based clinical research, such as the subjectivity of the answers given by the parents or legal guardians of the participating adolescents. In addition, neither confounding factors (such as gender, socioeconomic status, and objective measures of smoking) nor factors determining the level of allergen exposure were analyzed.

Future studies should include objective measures of pollutant exposure, aeroallergen exposure, and allergic sensitization, such as allergy testing and pulmonary function testing, in order to control for response bias. In addition, in order to avoid recall bias, cohort or case-control studies are preferable to cross-sectional studies.

Knowledge of asthma risk factors can aid families and health professionals in recommending preventive strategies to the community and parents of adolescents 
who are at risk of asthma and asthma exacerbation. Given the heterogeneity of the Brazilian population, further studies, conducted in other regions of Brazil, are needed in order to determine the role that the factors studied here, as well as other factors, have in the genesis of asthma.

\section{REFERENCES}

1. Yang HJ, Qin R, Katusic S, Juhn YJ. Population-based study on association between birth weight and risk of asthma: a propensity score approach. Ann Allergy Asthma Immunol. 2013;110(1):18-23 https://doi.org/10.1016/j.anai.2012.10.010

2. Asher MI, Montefort S, Björkstén B, Lai CK, Strachan DP Weiland SK, et al. Worldwide time trends in the prevalence of symptoms of asthma, allergic rhinoconjunctivitis, and eczema in childhood: ISAAC Phases One and Three repeat multicountry cross-sectional surveys. Lancet. 2006:368(9537):733-43. Erratum in: Lancet. 2007;370(9593):1128. https://doi.org/10.1016/S0140 6736(06)69283-0

3. Pearce N, Douwes J. The Latin American exception: why is childhood asthma so prevalent in Brazil? J Pediatr (Rio J). 2006;82(5):319-21. https://doi.org/10.2223/JPED.1538

4. Pearce N, Douwes J, Beasley R. Asthma. In: Detels R, McEwen J Beaglehole R, Tanaka H, editors. Oxford Textbook of Public Health. 4th ed. Oxford: Oxford University Press; 2002. p. 1255-77.

5. Douwes J, Pearce N. Asthma and the westernization 'package' Int J Epidemiol. 2002;31(6):1098-102. https://doi.org/10.1093/ ije/31.6.1098

6. Daley D. The evolution of the hygiene hypothesis: the role of early-life exposures to viruses and microbes and their relationship to asthma and allergic diseases. Curr Opin Allergy Clin Immunol. 2014;14(5):390-6. https://doi.org/10.1097/ACl.0000000000000101

7. Asher MI, Keil U, Anderson HR, Beasley R, Crane J, Martinez F, et al. International Study of Asthma and Allergies in Childhood (ISAAC) rationale and methods. Eur Respir J. 1995;8(3):483-91. https://doi.or g/10.1183/09031936.95.08030483

8. Worldwide variation in prevalence of symptoms of asthma, allergic rhinoconjunctivitis, and atopic eczema: ISAAC. The International Study of Asthma and Allergies in Childhood (ISAAC) Steering Committee. Lancet. 1998;351(9111):1225-32. https://doi org/10.1016/S0140-6736(97)07302-9

9. The International Study of Asthma and Allergies in Childhood (ISAAC [homepage on the Internet]. Auckland: ISAAC; c1998 [cited 2017 Mar 1]. ISAAC Phase Two--Modules. [Adobe Acrobat document; 72p.]. Available from: http://isaac.auckland.ac.nz/phases/phasetwo/ phasetwomodules.pdf

10. Mu M, Ye S, Bai M, Liu GL, Tong Y, Wang SF, et al. Birth weight and subsequent risk of asthma: a systematic review and metaanalysis. Heart Lung Circ. 2014;23(6):511-9. https://doi.org/10.1016/j. hlc.2013.11.018

11. Ortqvist $A K$, Lundholm $C$, Carlström $E$, Lichtenstein $P$, Cnattingius $S$, Almqvist $C$. Familial factors do not confound the association between birth weight and childhood asthma. Pediatrics. 2009;124(4):e737-43. https://doi.org/10.1542/peds.2009-0305

12. Seidman DS, Laor A, Gale R, Stevenson DK, Danon YL. Is low birth weight a risk factor for asthma during adolescence? Arch Dis Child. 1991;66(5):584-7. https://doi.org/10.1136/adc.66.5.584

13. Sin DD, Spier S, Svenson LW, Schopflocher DP, Senthilselvan A Cowie $R L$, et al. The relationship between birth weight and childhood asthma: a population-based cohort study. Arch Pediatr Adolesc Med. 2004;158(1):60-4. https://doi.org/10.1001/archpedi.158.1.60

14. Marbury MC, Maldonado G, Waller L. Lower respiratory illness, recurrent wheezing, and day care attendance. Am J Respir Crit Care Med. 1997;155(1):156-61. https://doi.org/10.1164/ ajrccm.155.1.9001305

15. Wissow LS, Gittelsohn AM, Szklo M, Starfield B, Mussman M. Poverty, race, and hospitalization for childhood asthma. Am J Public Health. 1988;78(7):777-82. https://doi.org/10.2105/AJPH.78.7.777

16. Ponsonby AL, Couper D, Dwyer T, Carmichael A. Cross sectional study of the relation between sibling number and asthma, hay fever, and eczema. Arch Dis Child. 1998;79(4):328-33. https://doi. org/10.1136/adc.79.4.328

17. Backman A, Björkstén F, Ilmonen S, Juntunen K, Suoniemi I. Do infections in infancy affect sensitization to airborne allergens and development of atopic disease? A retrospective study of seven-year-old children. Allergy. 1984;39(4):309-15. https://doi. org/10.1111/j.1398-9995.1984.tb00867.x
18. Krämer U, Heinrich J, Wjst M, Wichmann HE. Age of entry to day nursery and allergy in later childhood. Lancet. 1999;353(9151):450-4 https://doi.org/10.1016/S0140-6736(98)06329-6

19. Ball TM, Castro-Rodriguez JA, Griffith KA, Holberg CJ, Martinez FD, Wright AL. Siblings, day-care attendance, and the risk of asthma and wheezing during childhood. N Engl J Med. 2000;343(8):538-43. https://doi.org/10.1056/NEJM200008243430803

20. Celedón JC, Litonjua AA, Ryan L, Weiss ST, Gold DR. Day care attendance, respiratory tract illnesses, wheezing, asthma, and total serum IgE level in early childhood. Arch Pediatr Adolesc Med. 2002;156(3):241-5. https://doi.org/10.1001/archpedi.156.3.241

21. Cheng G, Smith AM, Levin L, Epstein T, Ryan PH, LeMasters GK, et al. Duration of day care attendance during infancy predicts asthma at the age of seven: the Cincinnati Childhood Allergy and Air Pollution Study. Clin Exp Allergy. 2014;44(10):1274-81. https://doi. org/10.1111/cea.12397

22. Nystad W. Daycare attendance, asthma and atopy. Ann Med 2000;32(6):390-6. https://doi.org/10.3109/07853890008995945

23. Burke W, Fesinmeyer M, Reed K, Hampson L, Carlsten C. Family history as a predictor of asthma risk. Am J Prev Med. 2003;24(2):160 9. https://doi.org/10.1016/S0749-3797(02)00589-5

24. Lima WL, Lima EV, Costa Mdo R, Santos AM, Silva AA, Costa ES Asthma and associated factors in students 13 and 14 years of age in São Luís, Maranhão State, Brazil [Article in Portuguese]. Cad Saude Publica. 2012;28(6):1046-56. https://doi.org/10.1590/S0102$311 \times 2012000600004$

25. Valadares MA, Gurgel RQ, Melo EV, Guimarães AM, Guedes $\mathrm{KM}$, Rocha NA, et al. Respiratory function in children of asthmatic mothers. J Pediatr (Rio J). 2013;89(2):158-63. https://doi. org/10.1016/j.jped.2013.03.007

26. Nasptiz CK, Solé D, Jacob CA, Sarinho E, Soares FJ, Dantas V, et al Sensitization to inhalant and food allergens in Brazilian atopic children by in vitro total and specific IgE assay. Allergy Project-PROAL [Article in Portuguese]. J Pediatr (Rio J). 2004;80(3):203-10. https:// doi.org/10.2223/1184

27. Brussee JE, Smit HA, van Strien RT, Corver K, Kerkhof M, Wijga $\mathrm{AH}$, et al. Allergen exposure in infancy and the development of sensitization, wheeze, and asthma at 4 years. J Allergy Clin Immunol. 2005;115(5):946-52. https://doi.org/10.1016/j.jaci.2005.02.035

28. Brunekreef B, von Mutius E, Wong G, Odhiambo J, García-Marcos L, Foliaki $\mathrm{S}$, et al. Exposure to cats and dogs, and symptoms of asthma, rhinoconjunctivitis, and eczema. Epidemiology. 2012;23(5):742-50. https://doi.org/10.1097/EDE.0b013e318261f040

29. Toledo MF, Rozov T, Leone C. Prevalence of asthma and allergies in 13- to 14-year-old adolescents and the frequency of risk factors in carries of current asthma in Taubaté, São Paulo, Brazil. Allergo Immunopathol (Madr). 2011;39(5):284-90. https://doi.org/10.1016/j. aller.2010.09.004

30. Jucá SC, Takano OA, Moraes LS, Guimarães LV. Asthma prevalence and risk factors in adolescents 13 to 14 years of age in Cuiabá, Mato Grosso State, Brazil [Article in Portuguese]. Cad Saude Publica. 2012;28(4):689-97. https://doi.org/10.1590/S0102311X2012000400008

31. Simpson A, Custovic A. Pet and the development of allergic sensitization. Curr Allergy Asthma Rep. 2005;5(3):212-20. https://doi. org/10.1007/s11882-005-0040-x

32. Beasley R, Crane J, Lai CK, Pearce N. Prevalence and etiology of asthma. J Allergy Clin Immunol. 2000;105(2 Pt 2):S466-72. https:// doi.org/10.1016/S0091-6749(00)90044-7

33. Landau LI. Parental smoking: asthma and wheezing illnesses in infants and children. Paediatr Respir Rev. 2001;2(3):202-6. https:// doi.org/10.1053/prrv.2001.0141

34. Tanaka K, Miyake Y, Arakawa M, Sasaki S, Ohya Y. Prevalence of asthma and wheeze in relation to passive smoking in Japanese children. Ann Epidemiol. 2007;17(12):1004-10. https://doi. org/10.1016/j.annepidem.2007.07.108

35. Janson $\mathrm{C}$. The effect of passive smoking on respiratory health in children and adults. Int J Tuberc Lung Dis. 2004;8(5):510-6. 
36. Montefort S, Ellul P, Montefort M, Caruana S, Grech V, Agius Muscat $\mathrm{H}$. The effect of cigarette smoking on allergic conditions in Maltese children (ISAAC). Pediatr Allergy Immunol. 2012;23(5):472-8. https:// doi.org/10.1111/j.1399-3038.2012.01276.x

37. Tsai $\mathrm{CH}$, Huang JH, Hwang BF, Lee YL. Household environmental tobacco smoke and risks of asthma, wheeze and bronchitic symptoms among children in Taiwan. Respir Res. 2010;11:11. https://doi.org/10.1186/1465-9921-11-11

38. Mitchell EA, Beasley R, Keil U, Montefort S, Odhiambo J; ISAAC Phase Three Study Group. The association between tobacco and the risk of asthma, rhinoconjunctivitis and eczema in children and adolescents: analyses from Phase Three of the ISAAC programme. Thorax. 2012;67(11):941-9. https://doi.org/10.1136/ thoraxjnl-2011-200901

39. Avanzini MA, Ricci A, Scaramuzza C, Semino L, Pagella F, Castellazz AM, et al. Deficiency of INFgamma producing cells in adenoids of children exposed to passive smoke. Int J Immunopathol Pharmacol. 2006;19(3):609-16. https://doi.org/10.1177/039463200601900317

40. Murray CS, Woodcock A, Smillie FI, Cain G, Kissen P, Custovic A, et al. Tobacco smoke exposure, wheeze, and atopy. Pediatr Pulmonol. 2004;37(6):492-8. https://doi.org/10.1002/ppul.20019 